\section{E-005 ANEURYSM TREATMENT WITH A NEW GENERATION FLOW DIVERTER}

${ }^{1} \mathrm{M}$ Marosfoi, ${ }^{1} E$ Langan, ${ }^{1} \mathrm{R}$ King, ${ }^{1} \mathrm{~F}$ Clarençon, ${ }^{1} \mathrm{I}$ Lylyk, ${ }^{1} \mathrm{O}$ Brooks, ${ }^{2} \mathrm{R}$ Slazas, ${ }^{1} \mathrm{~A}$ Puri, ${ }^{1} \mathrm{M}$ Gounis. ${ }^{1}$ Radiology, University of Massachusetts, Worcester, MA; ${ }^{2}$ Research and Development, Codman Neurovascular, Miami, FL

\subsection{6/neurintsurg-2016-012589.77}

Introduction The BRAVO flow diverter (Codman Neurovascular) is a variable count, braided implant made of nitinol wires for optimized wall apposition, with platinum wires for radiopacity. The implant also has laser-cut nitinol expansion rings at each end for instant opening and accurate placement. We hypothesize that there are no differences in aneurysm occlusion rates between the BRAVO and reference flow diverter (Pipeline Embolization Device, PED).

Materials and methods Twenty-four rabbits with saccular, elastase induced aneurysms were randomly assigned to receive a BRAVO or PED. Inclusion criteria for implant were the origin of the left common carotid artery at the brachiocephalic trunk, presence of an aneurysm and subclavian artery at the origin of the vertebral artery having a diameter $<4.5 \mathrm{~mm}$ (thereby excluding cases with significant elastase leakage). Following implant, longitudinal imaging studies were performed at 30,60, and 90 days by DSA with contrast injection via the central auricular artery. DSA was graded according to the scale of Darsaut et al., 2012; namely, $0=$ no change, $1 \leq 50 \%$ volume reduction, $2 \geq 50 \%$ volume reduction, $3=$ aneurysm filling confined to the neck, and $4=$ complete occlusion. Terminal angiography and histological analysis will be performed at 180 days. All animals were on dual antiplatelet therapy (DAPT, $10 \mathrm{mg} / \mathrm{kg}$ each of aspirin and clopidogrel) beginning at least 4 days before implant and continued until 30 days after implant.

Results Baseline characteristics (e.g., aneurysm size, neck size, PRU, parent vessel diameter) were not different between the two groups $(\mathrm{p}>0.05)$. Clopidogrel had a significant effect on PRU (231 \pm 38 at baseline vs $56 \pm 25$ after DAPT, $\mathrm{p}<0.0001)$. One animal assigned to BRAVO was excluded due to the diameter of the subclavian artery $>4.5 \mathrm{~mm}$. Another animal in the PED group was excluded due to distal migration of the device following deployment leading to incomplete coverage of the aneurysm neck. All remaining devices were accurately deployed. Longitudinal imaging studies have shown progressive healing of the aneurysms for both devices, with approximately half of the aneurysms completely occluded at 90 days (Figure 1). There are no differences between the occlusion rates of the devices.

Conclusion A new flow diverter has been designed to enable accurate placement with self-expanding rings at both ends of the device. This new generation device has equivalent occlusion rates in a rabbit model of saccular aneurysms as compared to the reference device.

\section{REFERENCE}

1 Darsaut TE, et al. AJNR 2012;33:2004-2009.

Disclosures M. Marosfoi: None. E. Langan: None. R. King: None. F. Clarençon: None. I. Lylyk: None. O. Brooks: None. R. Slazas: 5; C; Codman Neurovascular. A. Puri: 2; C; Codman Neurovascular. M. Gounis: 1; C; Codman Neurovascular. 2; C; Codman Neurovascular.

\section{E-006 BRAINSTEM REPERFUSION INJURY FOLLOWING ENDOVASCULAR TREATMENT OF POSTERIOR CIRCULATION ISCHEMIA}

${ }^{1} \mathrm{~T}$ Higashimori, ${ }^{1} \mathrm{~J}$ Kim, ${ }^{1} \mathrm{D}$ Sandhu, ${ }^{2} \mathrm{C}$ Streib, ${ }^{3} \mathrm{R}$ Tummala. ${ }^{1}$ Neurosurgery, Neurology and Radiology, University of Minnesota, Minneapolis, MN; ${ }^{2}$ Neurology, University of Minnesota, Minneapolis, MN; ${ }^{3}$ Neurosurgery, University of Minnesota, Minneapolis, MN

\subsection{6/neurintsurg-2016-012589.78}

Introduction Reperfusion injury is a recognized but fairly uncommon consequence of revascularization of anterior circulation large vessel occlusion. It has not been described in the posterior circulation, perhaps because of the lower incidence of posterior circulation occlusive disease and because many of these lesions were not historically amenable to revascularization. We describe two cases of brainstem hemorrhage following revascularization of vertebrobasilar arterial occlusion.

Methods The medical records and images of patients who underwent revascularization of the posterior circulation were reviewed. Cases were identified from our institutional neuroendovascular database.

Results Two patients with brainstem hemorrhages following angioplasty and stent placement in the posterior circulation were identified. The first patient was a 68 year-old woman with systemic lupus erythematosus and multiple, recurrent posterior circulation strokes. She had bilateral vertebral artery occlusion with poor angiographic collaterals. She underwent uneventful placement of a balloon mounted stent in the left vertebral artery, and a good angiographic result was obtained. Thirty minutes later, she became comatose and a massive pontine hemorrhage was discovered.

The second patient was a 78 year-old woman with recurrent syncope and scattered cerebellar strokes. She had flow limiting basilar artery stenosis and required systolic blood pressures $>180 \mathrm{~mm} \mathrm{Hg}$ to maintain consciousness. She could not be maintained without vasopressors and endovascular treatment was performed. She underwent successful angioplasty and stent placement. She was in good neurological
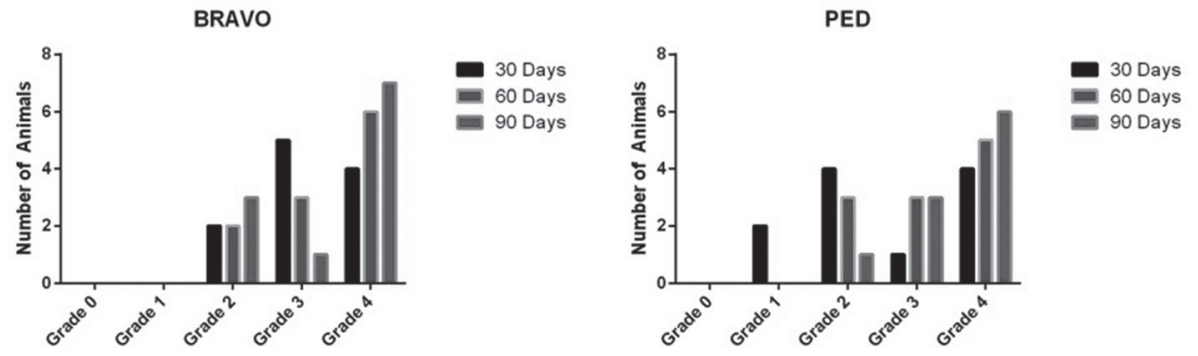

Abstract E-005 Figure 1 Grade of aneurysm occlusion for each device group over time 
condition initially, but 12 hours later she became comatose with a large pontine and midbrain hemorrhage. Both patients expired.

Conclusion Because all other causes seemed implausible, we concluded that both patients died of brainstem reperfusion injury. Because of the improved ability to treat vertebrobasilar occlusive disease, reperfusion injury in the posterior circulation may be increasingly recognized and characterized.

Disclosures T. Higashimori: None. J. Kim: None. D. Sandhu: None. C. Streib: None. R. Tummala: None.

\section{E-007 RESULT OF STENT-ANGIOPLASTY WITH WINGSPAN STENT FOR SYMPTOMATIC INTRACRANIAL STENOSIS}

S You. Neurosurgery, University of Ulsan College of Medicine, Gangneung Asan Hospital, Gangneung-si, Republuic of Korea

\subsection{6/neurintsurg-2016-012589.79}

Purpose The purpose of this study is to investigate the treatment results, and procedure-related complications of stentangioplasty for symptomatic intracranial arterial stenosis with Wingspan stent and Gateway balloon.

Materials and methods From May. 2010 to May 2015, 76 patients (52 males, 24 females, mean age: $66.6 \pm 8.9$ years) with symptomatic intracranial arterial stenosis were treated. Inclusion criteria are acute and/or subacute symptomatic infarction or repeated transient ischemic attack (TIA) (infarction vs. TIA: 39 vs. 37) and severe stenosis related to symptoms confirmed with catheter angiography. The numbers of stenotic lesions were 29 cases on ICA, 34 on MCA, and 13 on vertebrobasilar (V-B) artery. All of the used stents for treatment were Wingspan self-expanding stent and Gateway balloon. Mean NIHSS at admission was $1.4 \pm 1.9$, and mean stenosis rate was $76.8 \pm 6.2 \%$. Clinical status (including NIHSS) and angiographic results were assessed retrospectively. Results Stents were successfully deployed at first trial in almost all cases except only two cases due to tortuous ICA course $(97.4 \%)$, and in one case successful stenting was done at second trial (98.7\%). Periprocedural complications occurred in 11 cases (14.5\%), and symptomatic cases were only $6(7.9 \%$, transient vs. permanent: $4(5.3 \%$ vs. $2.6 \%)$. Of 76 cases 67 were followed clinically over 6 months $(88.2 \%)$ and the mean follow-up period was $25.8 \pm 20.0$ months). Angiographic follow-up was performed in 57 cases $(75.0 \%$. $13.9 \pm 11.8$ months). The mean NIHSS after stent-angioplasty was $0.8 \pm 1.7$ and $0.5 \pm 1.7$ at last clinical follow-up day. Poststenting residual stenosis was $8.7 \pm 13.0 \%$, and $14.8 \pm 25.3 \%$ at last angiographic follow up. In-stent restenosis over $50 \%$ occurred in 7 cases $(7 / 57,12.3 \%)$, and 6 cases were retreated successfully with Gateway balloon (3) or Drugeluting balloon (3). Symptomatic infarctions were occurred in 4 of $76(5.3 \%)$ patients during the clinical follow-up period. Conclusion Stent-angioplasty with Wingspan self-expanding stent appeared to be safe and effective for intracranial arterial stenotic disease. However, it should prompt more strict selection criteria and desperate angiographic follow-up for better clinical results.

Disclosures S. You: None.

\section{PATIENT OUTCOMES FOLLOWING TREATMENT OF HIGH FLOW VASCULAR LESIONS OF THE ANTERIOR CRANIAL FOSSA AND ORBIT}

${ }^{1} \mathrm{~A}$ Moraff, ${ }^{1} \mathrm{R}$ Dodd, ${ }^{2} \mathrm{M}$ Marks, ${ }^{2} \mathrm{H}$ Do, ${ }^{1} \mathrm{G}$ Steinberg, ${ }^{1} \mathrm{~S}$ Chang, ${ }^{2} \mathrm{~J}$ Heit. ${ }^{1}$ Neurosurgery, Stanford University, Stanford, $C A$; ${ }^{2}$ Interventional Neuroradiology, Stanford University, Stanford, CA

\subsection{6/neurintsurg-2016-012589.80}

Introduction High flow vascular lesions of the anterior cranial fossa and orbit (HFVL) include arteriovenous malformations and dural arteriovenous fistulae located within the orbit, periorbital region, ethmoid sinuses, the anteroinferior frontal lobes, or within the dura of the anterior cranial fossa. Rupture of HFVL may result in intracranial hemorrhage, so these lesions typically undergo treatment even when discovered for other reasons. HFVL may be treated by trans-arterial endovascular embolization, surgical ligation, radiosurgery, or a combination of these approaches, but the most optimal treatment is not well defined. We determined patient outcomes and HFVL obliteration after treatment.

Methods We retrospectively reviewed all patients referred for diagnostic angiography or endovascular embolization of HFVL at our neurovascular referral center over an 8 year period. Patient demographic, treatment, and outcome data were deterred from the medical record. DSA, CT, and MRI studies were reviewed for HFVL characteristics and obliteration after treatment.

Results HFVL were identified in 11 patients (five females and six males) ranging in age from 8 to 76 years (mean 53 years). Presenting symptoms included headaches (nine patients; 82\%), visual symptoms (five patients; 45\%), intracranial hemorrhage (two patients; 18\%), tinnitus (one patient; 9\%), or no symptoms (one patient; 9\%). Nine patients (81\%) had medical comorbidities, but none had a hypercoagulable disorder or prior trauma. The HFVL were comprised of seven dural arteriovenous fistulae (64\%) and four arteriovenous malformations (36\%). The ophthalmic artery was the dominant feeding vessel in 10 patients (91\%). 10 patients (91\%) were treated, including embolization via the ophthalmic artery (four patients; $36 \%$ ), embolization followed by surgical ligation (3 patients; $27 \%$ ), embolization followed by radiosurgery (one patient; 9\%), surgical ligation alone (one patient; 9\%), or radiosurgery alone (one patient; 9\%). Endovascular embolization was performed with Onyx (six patients; 75\%) or n-BCA (two patients; 25\%) HFVL cure was achieved in six patients $(55 \%)$, including three patients treated by embolization alone, two treated by embolization and surgical ligation, and one by surgery alone. One patient treated by embolization alone developed a post-treatment partial visual deficit, but there were no other complications related to treatment. No patient deaths occurred.

Conclusions HFVL are uncommon lesions that are challenging to treat. Endovascular embolization alone or in combination with surgery results in HFVL obliteration in $50 \%$ of patients with an acceptable safety profile. Further studies should determine whether radiosurgery alone or in combination with endovascular embolization results in high rates of HFVL cure. Disclosures A. Moraff: None. R. Dodd: None. M. Marks: None. H. Do: None. G. Steinberg: None. S. Chang: None. J. Heit: None. 